NBSIR $77-864$

FILE COPY

DO NO'T REMOVE

LIQUEFIED NATURAL GAS RESEARCH

\author{
at the
}

\title{
NATIONAL BUREAU OF STANDARDS
}

\author{
PROGRESS REPORT FOR THE PERIOD \\ 1 JANUARY - 30 JUNE 1977
}

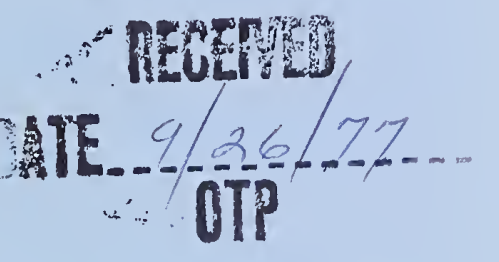

D.E. Diller, Editor

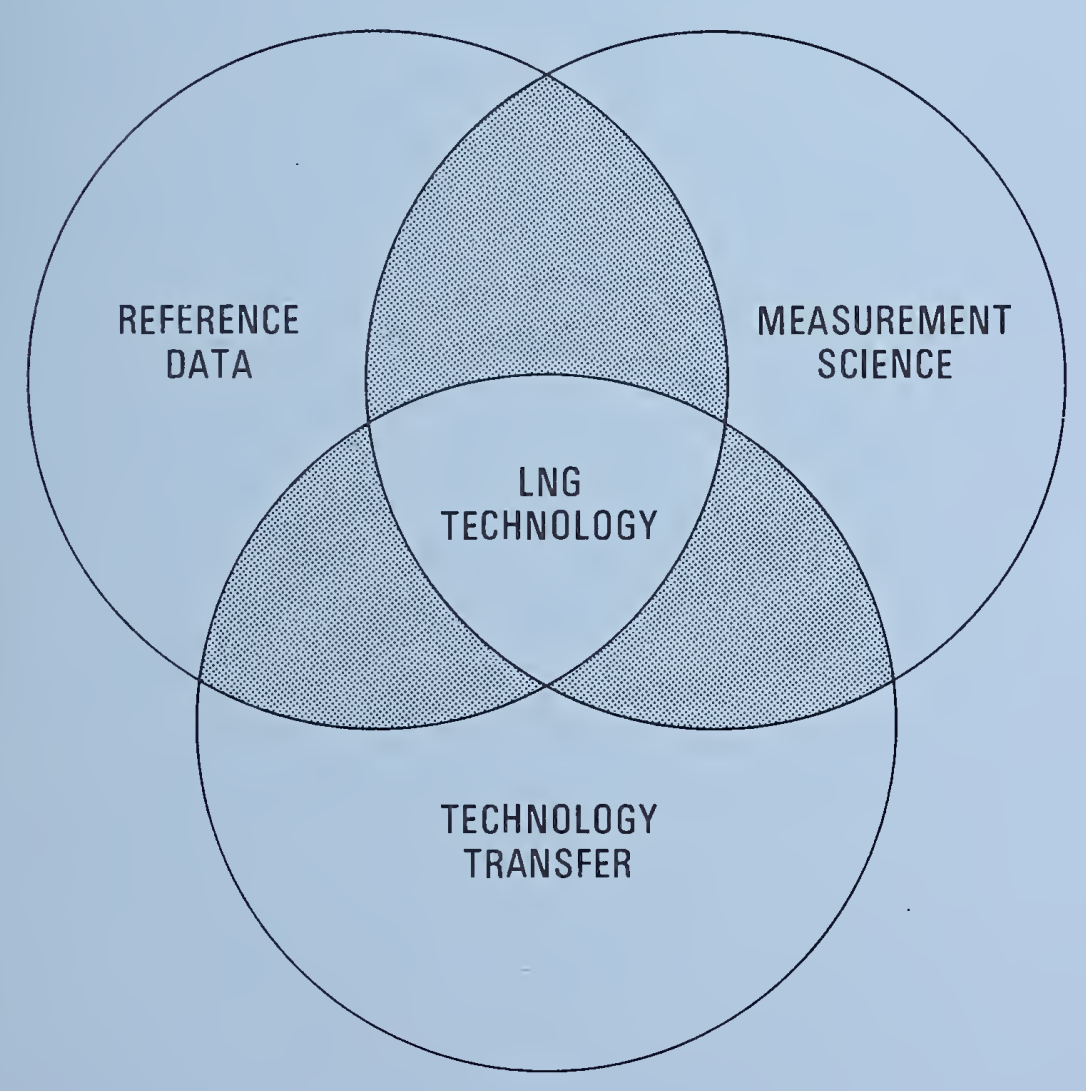



NBSIR $77-864$

\title{
LIQUEFIED NATURAL GAS RESEARCH
}

\author{
at the
}

\section{NATIONAL BUREAU OF STANDARDS}

D.E. Diller, Editor

Cryogenics Division

Institute for Basic Standards

National Bureau of Standards

Boulder, Colorcdo 80302

Progress Report for the Period

1 January - 30 June 1977

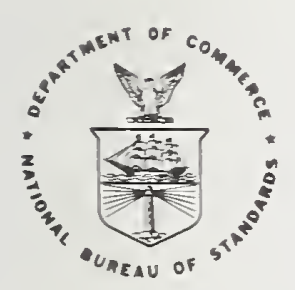

U.S. DEPARTMENT OF COMMERCE, Juanita M. Kreps, Secretary Sidney Harman, Under Secretary Jordan J. Baruch, Assistant Secretary for Science and Technology

NATIONAL BUREAU OF STANDARDS, Ernest Ambler, Acting Director 


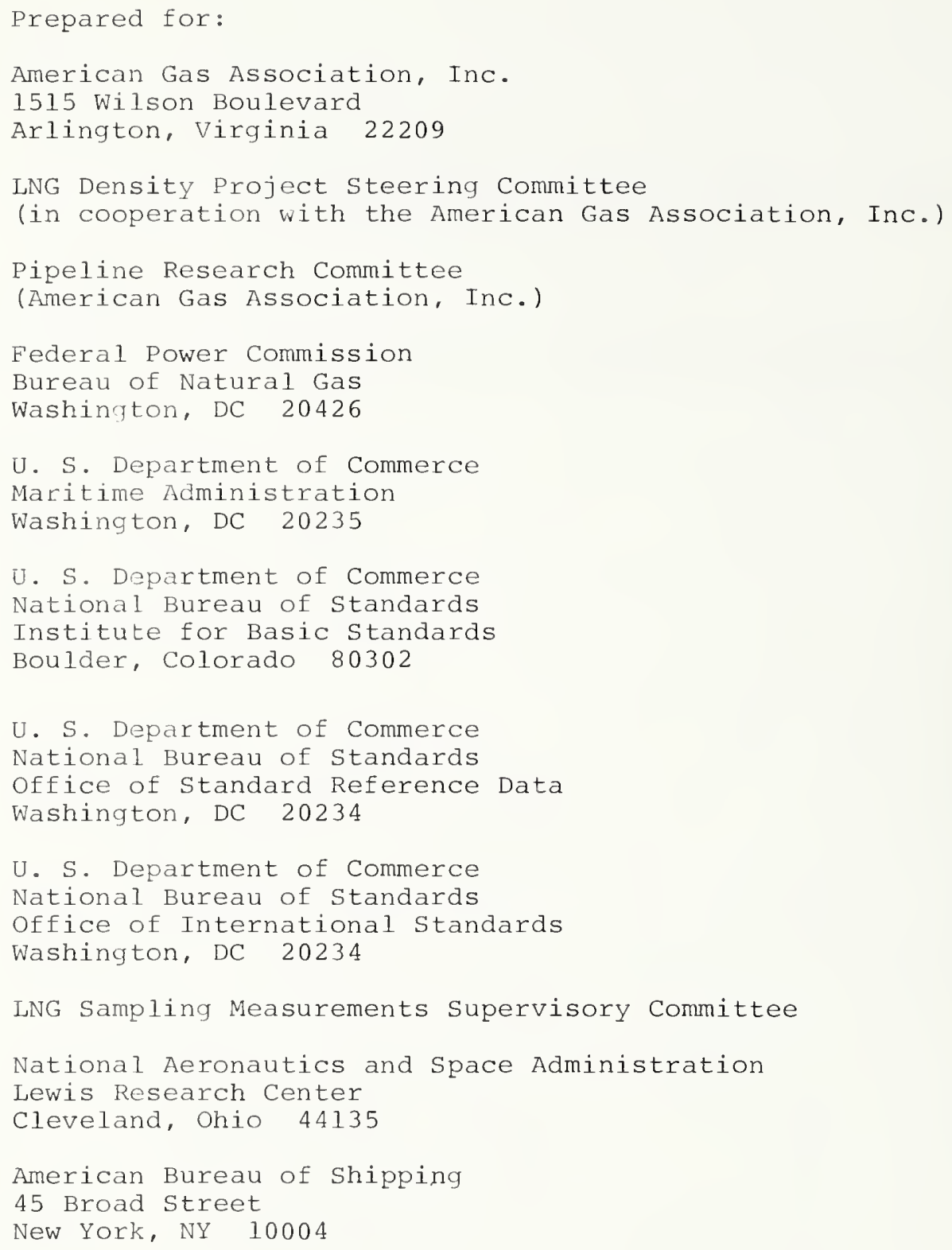




\section{ABSTRACT}

Twenty-six cost centers, supported by six other agency sponsors in addition to NBS, provide the basis for liquefied natural gas (LNG) research at NBS. During this six-month reporting period the level of effort was over $20 \mathrm{man}$-years/year with funding expenditures of over $\$ 500,000$. This integrated progress report, to be issued in January and July, is designed to:

1) provide all sponsoring agencies with a semi-annuai and an annual report on the activities of their individual programs;

2) inform all sponsoring agencies on related research being conducted at the Cryogenics Division;

3) provide a uniform reporting procedure which should maintain and improve communication while minimizing the time, effort and paperwork at the cost center level.

The contents of this report will augment the quarterly progress meetings of some sponsors, but will not necessarily replace such meetings. Distribution of this document is limited and intended primarily for the supporting agencies. Data or other information must be considered preliminary, subject to change and unpublished, and therefore not for citation in the open literature.

Key words: Cryogenics; liquefied natural gas; measurement; methane; properties; research. 
I. REFERENCE DATA
a) THERMOPHYSICAL PROPERTIES DATA FOR PURE COMPONENTS AND MIXTURES OF LNG COM- PONENTS (American Gas Association, Inc.; NASA Lewis Research Center)
b) FLUID TRANSPORT PROPERTIES (NBS-Office of Standard Reference Data)
C) PROPERTIES OF CRYOGENIC FLUIDS (NBS)
d) PROPERTIES OF CRYOGENIC FLUID MIXTURES (NBS: NBS-Office of Standard Reference Data; $\mathrm{AGA}$ )
e) DENSITIES OF LIQUEFIED NATURAL GAS MIXTURES (LNG Density Project steering Committee - AGA)
f) PROGRAM FOR REDUCING THE COST OF LNG SHIP HULL CONSTRUCTION -- PHASE II SHIP STEEL IMPROVEMENT PROGRAM (Maritime Administra- tion)

2751430 . 2752430 and 2753430

2750460

2756579 2750161 (American Gas Association, Inc.; National Bureau of Standards)

a) LNG SAMPLIÑG MEASUREMENT STUDY (LNG Sampling Measurements Supervisory Committee)

III. TECHNOLOGY TRANSFER

a) SURVEY OF CURRENT LITERATURE ON LNG AND METHANE (American Gas Association, Inc.)

b) LIQUEFIED NATURAL GAS TECHNOI,OGY TRANSFER (Maritime Administration; American Gas Association, Inc.; American Bureau of Shipping; NBS-Office of Standard Reference Data)

C) OIML JOINT SECRETARTAT ON LNG MEASUREMENTS (American Gas Association, Inc.; NBS-Office of International standards; NBS-Cryogenics Division)
2759574 
1. Title. THERMOPHYSICAL PROPERTIES DATA FOR PURE COMPONENTS AND MIIXTURES OF LNG COMPONENTS

Principal Investigators. R. D. Goodwin, H. M. Roder, G. C. Straty, R. Tsumura*, W. M. Haynes, and R. D. McCarty

2. Cost Center Number. 2750574, 2750548

3. Sponsor Project Identification. American Gas Association, Inc., Project BR-50-10. National Aeronautics and Space Administration, Lewis Research Center, Purchase Order C-78014-C.

4. Introduction. Accurate phase equilibrium, equation of state (PVT), and thermodynamic properties data are needed to design and optimize gas separation and liquefaction processes and equipment as well as heat transfer calculations. Fccurate data for the pure components and selected mixtures of hydrocarbon systems will permit developing comprehensive accurate predictive calculation methods which take into account the dependence of the thermophysical properties of mixtures on the composition, temperature, and density.

This project will provide comprehensive accurate thermophysical properties data and predictive calculation methods for compressed and liquefied hydrocarbon gases and their mixtures to support the development of LNG technology at NBS and throughout the fuel gas industry. It will also serve as the base for a comprehensive mixtures prediction methodology.

5. Objectives or Goals. The objectives of our work are the determination of comprehensive accurate thermophysical properties data and predictive calculation methods for the major pure components (methane, ethane, propane, butanes, and nitrogen) and selected mixtures of liquefied natural gas and hydrocarbon mixtures at temperatures between $90 \mathrm{~K}$ and $300 \mathrm{~K}$ and at pressures up to $35 \mathrm{MPa}$ (5000 psi). Our goal is to provide a range and quality of data that will be recognized as definitive or standard for all foreseeable low temperature engineerirg calculations.

6. Background. Liquefied naturai gas is expected to supply an increasing percentage of the United States' future energy requirements. It is likely that massive quantities of liquefied natural gas will be imported during the years 1978 - 1990. Ships and importation terminals are being built for transporting, storing, and vaporizing liquefied natural gas for distribution. Accurate physical and thermodynamic properties data for compressed and liquefied natural gas and hydrocarbon mixtures are needed to support these projects. For example, accurate compressibility and thermodynamic properties data are needed to design and optimize liquefaction and transport processes; accurate data for the heating value, which for liquefied natural gas mixtures depends on the total volume, the density, and the composition, are needed to provide a basis for equitable custody transfer. Accurate mixtures prediction methods are needed for use in automated heat transfer calculations.

Accurate thermodynamic properties data for liquefied gas mixtures must be based on precise compressibility and calorimetric measurements; compressibility data give the dependence of thermodynamic properties on pressure and density (at fixed temperatures); calorimetric data give

\footnotetext{
“ Consejo Nacional de Ciencia y Tecnologia (CONACYT) Mexico City. Currently a guest worker with the Cryogenics Division, National Bureau of Standards, Institute for Basic Standards in Boulder, Colorado.
} 
the dependence of thermodynamic properties on temperature (at fixed pressures and densities). It is impossible, however, to perform enough compressibility and calorimetric measurements directly on multicomponent mixtures to permit accurate interpolation of the data to arbitrary composition, temperatures and pressure. Instead, thermodynamic properties data for multicomponent mixtures must usually be predicted (extrapolated) from a limited number of measurements on the pure components and their binary mixtures. This project was initiated to provide the natural gas and aerospace industry with comprehensive accurate data for pure compressed and liquefied methane, the most abundant component in LNG mixtures. We have published National Bureau of Standards Technical Note 653, "Thermophysical Properties of Methane, From 90 to $500 \mathrm{~K}$ at Pressures to 700 Bar," by Robert D. Goodwin (April 1974), and National Bureau of Standards Technical Note 684, "Thermophysical Properties of Ethane, From 90 to $600 \mathrm{~K}$ at Pressures to 700 Bar," by Robert D. Goodwin, H. M. Roder, and G. C. Straty (August 1976). These reports contain the most comprehensive and accurate tables available for the thermophysical properties of pure gaseous and liquid methane and ethane, and provide accurate basis for calculating thermophysical properties data for LNG and hydrocarbon mixtures.

7. Program and Results.

7.1 Ethane, Specific Heat Data -- H. M. Roder

This phase of the program is complete. I'wo manuscripts describing the results of the research have been published:

H. M. Roder, Measurements of the Specific Heats, $C_{\sigma}$ and $C_{V}$, of Dense Gaseous and I.iquid Ethane, J. Res. Nat. Bur. Stand. (U.S.), Vol 80A, No. 5, 739-59 (Sep-Oct 1976).

H. M. Roder, The Heats of Transition of Solid Ethane, J. Chem. Phys. Vol 65, ivo. 4, 1371-3 (Aug 1976).

7.2 Ethane, Sound Velocity Data -- R. Tsumura, G. C. Straty

This phase of the program is complete. The results of the research have been reported in the following publication:

R. Tsumura, G. C. Straty, speed of Sound in Saturated and Compressed Fluid Ethane, Cryogenics Vol 17, No. 4, 195-200 (Apr 1977).

7.3 Ethane, Thermophysical Properties Data -- R. D. Goodwin

The manuscript, IJational Bureau of Standards Technical Note 684 , "Thermophysical Properties of Ethane, From 90 to $600 \mathrm{~K}$ at Pressures to 700 Bar," by R. D. Goodwin, Hi. M. Roder, and G. C. Straty (August 1976) has been published and distributed.

\subsection{Propane, Thermophysical Properties Data -- R. D. Goodwin}

Available, published physical properties data, acquired through our Cryogenic Data Center, have been evaluated and formulated as required for thermodynamic computations. "ihese numerous properties now have been used to compute a complete set of provisional tables of thermodynamic functions.

The manuscript, "Provisional Thermodynamic Functions of Propane, From 85 to $700 \mathrm{~K}$ at Fressures to $700 \mathrm{Bar}$," is complete and has been released by the NBS Editorial Review Board. This will be published as National Bureau of Standards Internal Report, NBSIR 77-860, within six weeks.

Work will commence in one to two months on measuring and analyzing specific heat data for liquefied and gaseous propane. 
7.5 Propane, Experimental Measurements -- W. M. Haynes

A new apparatus has been developed for pressure, temperature, density, composition, and dielectric constant measurements on liquids and liquid mixtures at temperatures between 70 and $350 \mathrm{~K}$ and at pressures to $35 \mathrm{MPa}$ (approximately $5000 \mathrm{psi}$ ). This apparatus, which incorporates a magnetic suspension technique in the density determination, is significantly different and more versatile than the instrument previously used in the LNG Density Project.

The overall dimensions of the new copper cell are roughly the same as the cell used previously, except for an increase in the thickness of the walls required for use at higher pressures. The internal free volume is approximately $40 \mathrm{~cm}^{3}$, or twice that of the previous cell. This increase in the internal free volume of the cell is due largely to the complexity in the assembly of the capacitor and magnetic sensor, their supports, and seven coaxial leads. As long as enough mixture can be prepared to fill the cell (which is the case for all mixtures being considered here) the additional free volume presents several advantages; e.g., the liquid-to-gas volume ratio is larger.

A new window assembly, which can be used to pressures of 5,000 psi or larger, has been tested. The assembly consists of a sapphire disk (3/4" diameter x 1/4" thick), indium gasket, asbestos rubber backing material and stainless steel plug and ring with four 1/4-20 stainless steel set screws to provide a pressure- and vacuum-tight seal. It has a $1 / 4$ inch diameter viewing area and is naturally located at the height at which the magnetic float is suspended. With this apparatus the liquid-vapor interface cannot be observed visually. This is not necessary in determining when the cell is full of liquid. This can be accomplished by monitoring the pressure and temperature of the cell and its contents. The complexity of the apparatus and the high pressure consideration made impractical a visual observation of the liquid-vapor interface.

The new cell will have an additional capillary into the top of the cell, which is primarily for (vapor) pressure measurements in a capillary that is independent of the recirculation lines. The recirculation heat exchanger length and volume have been reduced considerably since the previous measurements exhibited that there was little heat load on cell during recirculation. It is now possible to fill the cell from either the top or bottom, or both simultaneously.

A platinum resistance thermometer is again the primary temperature sensor and is located at approximately the same vertical position as the magnetic float. It is attached with indium in a container softsoldered to the cell. Due to the high pressures, it was not practical to install a vapor bulb inside the cell. However, two vapor bulbs (each with an internal volume of $2 \mathrm{~cm}^{3}$ ) have been installed at the ends of the cell in close thermal contact (soft-solder) with the outside surface of the cell. These will be used to monitor temperature gradients along the length of the cell. Differential thermocouples (chromelconstantan) have been located at the same positions as the vapor bulbs and the voltage output from these will be used to null temperature differences along the length of the cell.

An existing cryostat, which could be used to lower temperatures than that of the previous work, has been extensively modified to be compatible with the magnetic suspension densimeter. Cooling is accomplished by reflux action or exchange gas (along with conduction down leads and capillaries) through a central tube that passes through the liquid nitrogen reservoir and is attached to the cell lid. (Means have also been provided, if needed, for cooling at the bottom of the cell through tubes connected to a copper ring soft-soldered to the cylindrical surface of the cell near its bottom.) Above the cell on the central tube (thinwalled stainless steel) a giard ring is used to thermally temper the 
electrical wires that are wound on the cell. The temperature of the guard ring is controlled at the same temperature as the cell through the use of a chromel-constantan differential thermocouple between the guard ring and cell and the use of a vapor bulb placed in good thermal contact with the guard ring. For temperature control, a $100 \Omega$ heater has been wound on the guard ring and four independent 125-160 $\Omega$ heaters on the cell along its length.

The pressure measurements will be accomplished using the same procedures as employed in the earlier work. An oil dead-weight gauge has been connected to determine the pressure of the fluid inside the cell, especially at pressures larger than $2 \mathrm{~atm}$. or $30 \mathrm{psi}$. At low pressures, the calibrated spiral quartz Bourdon gauges will be used as before.

A differential capacitance sensor is being used to detect the motion of the magnetic float; previously a linear differential transformer (LDT) was utilized for this purpose. A differential capacitance sensor is being used to alleviate the problems of pressurized fluid penetrating the windings of the inductance coils and of changes in the position of the float due to changes in the dielectric constant of the test fluid. The new sensor has approximately the same sensitivity as the LDT and has been used to support the float without problems. Final adjustments and tests have not been carried out to eliminate the dependence of the float height on the dielectric constant of the fluid. These adjustments will not be carried out until the apparatus is completely assembled since all adjustments are made to electric components outside the cryostat. The servosystem used in the previous work was modified to be compatible with the new sensor. With the new cryostat there is no mechanical mechanism to change the position of the float. All changes in the float position, if needed due to thermal expansion effects in cryostat, cell, supports, etc., will be accomplished electronically with coarse and fine capacitors located at the top of the cryostat. With these capacitors it is easy to change and fix the float's height within the desired precision, approximately $10^{-3} \mathrm{~mm}$. The same $125 \mathrm{x}$ microscope as used in the previous work, except for different lenses, will be used as the primary means for determining the position of the float.

A new main coil (of larger diameter to be compatible with new cell) has been wound from epoxy-coated aluminum foil. The maincoil consists of two coils epoxied to a central quartz tube. The quartz tube is supported on a fiberglass plate that is supported by (three) one-inch diameter quartz rods. Water-cooled copper plates have been placed in good thermal contact with all faces of the two coils. No problems have been encountered with this arrangement for mounting and cooling the coils at currents to $1.5 \mathrm{~A}$. (270 watts). (The outside diameter of the new main coil was made less than the inside diameter of the gradient coils used in the previous work in case a need for a three coil system cropped up again.) A new calibrated $0.5 \Omega$ standard resistor, which can withstand currents of $2 \pi$ without degradation of its specifications, has been obtained and placed in an insulated oil bath. This resistor is in series with the main coil and the measurement of the voltage drop across this resistor enters directly into the calculation of density.

A capacitor with slotted concentric cylinders has been placed just above the density sensor. It will be used for simultaneous dielectric constant measurements on the fluids for which PVTx data are obtained. The capacitor is made from copper and has a capacitance of approximately 20 $\mathrm{pF}$ in air at room temperature. It has been tested in air and in liquid hexane at room temperature. It appears to be mechanically stable and its overall stability is such that the capacitance can be determined routinely to $0.0001 \mathrm{pF}$.

whe entire apparatus is in the final stages of assembly. Barring unforeseen difficulties, it should be completely assembled within the next week or so. Performance tests will follow and hopefully be 
completed the first part of August. The float that has been wellcharacterized from the previous work will be used again.

The cell and window assembly have been tested to pressures above 6,000 psig at room temperature and at $76 \mathrm{~K}$ using helium gas. The cell has been cycled between these temperature extremes five times. No leaks were encountered.

The "guts" of the apparatus (the capacitor, differential capacitance sensor, and associated parts) survived the severe test of a sudden immersion in liquid nitrogen and subsequent rapid warmup to room temperature. The cryostat has been leak checked while the reservoir was full of liquid nitrogen. The systems for handling (charging cell, sampling, recirculation, pressure measurements and control, vacuum, vent, etc.) of the fluids under study have been assembled and leak checked.

\subsection{Calculational Methods -- R. D. McCarty}

of the four calculational methods evaluated and optimized under another cost center (2751574), the present investigation has shown the extended corresponding states method to be the most promising method for predicting the thermophysical properties of mixtures over a wide range of temperature and pressure. The rigorous mapping of a model for the equation of state of methane to a model for the equation of state for nitrogen has been accomplished via the extended corresponding states theory. Determination of the binary interaction parameters using PVTx and phase equilibria data simultaneously, together with non-linear least squares parameter estimation techniques, is now in progress.

8. Problem Areas. None.

9. Funding. January 1 - June 30, 1977.

Man-years expended

Equipment and/or Services Purchased

Total Reporting Period Cost

Balance Remaining
1.1

$11.8 \mathrm{~K} \$$

$81.2 \mathrm{~K} \$$

$72.3 \mathrm{~K} \$$

10. Future Plans.

Objectives and Schedule: Quarter

Analyze and report available physical properties data for propane.

Prepare and performance test PVT and dielectric constant properties apparatus for propane.

Evaluate and optimize promising calculation methods for the thermodynamic properties of methane-nitrogen mixtures.

Measure, analyze and report specific heat data for propane. 
1. Title. FLUID TRANSPORT PROPERTIES

Principal Investigator. Howard J. M. Hanley

2. Cost Center Number. 2750124

3. Sponsor Project Identification. NBS-Office of Standard Reference Data

4. Introduction. Methods for predicting che transport properties of fluid mixtures are unreliable and data are scarce. Prediction methods are needed, however, to supply the necessary design data needed to increase efficiency and reduce costs.

5. Objectives or Goals. The long range or continuing goal of the program is to perform a systematic study of the theories and experimental measurements relating to transport properties, specifically the viscosity and hermal conductivity coefficients, of simple mixtures over a wide rarge of experimental conditions. The specific objectives of the progiam include: 1) the systematic correlation of the transport properties of simple binary mixtures and the development of prediction techniques, 2) development of a mixture theory for the dilute gas region and the dense gas and liquid regions, 3) extension of the theory and prediction techniques to multicomponent systems, and 4) suggested guidelines for future areas of experimental work.

6. Background. A continuing program has successfully expanded the stateof-the-art of transport phenomena for pure fluids. Information for pure fluids is required as a prerequisite for mixture studies. The theory of transport phenomena has been developed end applied to produce practical numerical tables of the viscosity, thermal conductivity and diffusion coefficients of simple fluids: Ar, $\mathrm{Kr}, \mathrm{Xe}, \mathrm{N}_{2}, \mathrm{O}_{2}, \mathrm{~F}_{2}, \mathrm{He}, \mathrm{H}_{2}, \mathrm{CH}_{4}$, $\mathrm{C}_{2} \mathrm{H}_{6} \cdot$ (4)

Recent work has extended this approach to propane. It has been shown that a successful mixture program can emerge from combining the results for pure fluids with equation of state studies. The equation of state work is being carried out by other investigators in this laboratory.

7. Program and Results. A procedure to predict the transport properties of mixtures has been developed via corresponding states. (1-2) The method has been shown to be satisfactory. Current studies include investigating the effects of internal degrees of freedom on the thermal conductivity coefficient and the behavior of the transport coefficients near a critical point. (2) The program has been expanded by the addition of James C. Rainwater, a NBS/NRC Postdoctoral Research Fellow, who is investigating the theoretical background.

8. Problem Areas. The lack of suitable experimental mixture transport properties data for comparison purposes is the main problem. Also equation of state (PVT) data for mixtures are reeded.

9. Funding. January 1 - June 30, 1977.

$\begin{array}{llr}\text { Allocation } & 60.0 \mathrm{~K} \$ \mathrm{Yr} . & \\ \text { Labor } & 0.5 \mathrm{MY} & 32.8 \mathrm{K \$} \\ \text { Other costs } & & 3.6 \mathrm{~K} \$ \\ \quad \text { Total } & & 36.4 \mathrm{~K} \$\end{array}$

10. Future Plans. The transport properties of ethylene will be investigated. The corresponding states predictive procedure for mixtures will be expanded in line with the concurrent equation of state studies. 


\section{References}

1. H. J. M. Hanley, Prediction of the Viscosity and Thermal Conductivity Coefficients of Mixtures, Cryogenics Vol 16, No. 11, 643-51 (Nov 1976); H. J. M. Hanley, Prediction of the Thermal Conductivity of Fluid Mixtures, Proceedings 7 th ASME Conf. on Thermophysical properties.

2. H. J. M. Hanley, Transport Coefficients in the One-Fluid Approximation: Behavior in the Critical Region, Mol. Phys. (1977).

3. H. J. M. Hanley, W. M. Haynes and R. D. MCCarty, The Viscosity and Thermal Conductivity Coefficients for Dense Gaseous and Liquid Methane, J. Phys. Chem. Ref. Data Vol 6, No. 2, 597-609 (1977).

4. H. J. M. Hanley, K. E. Gubbins and S. Murad, A Correlation of the Existing Viscosity and Thermal Conductivity Coefficients of Gaseous and Liquid Ethane, J. Phys. Chem. Ref. Data Vol 6, No. 4, (1977). 
1. Title. PROPERTIES OF CRYOGENIC FLUIDS

Principal Investigators. G. C. Straty, H. M. Roder, L. A. Weber, B. J. Ackerson, and D. E. Diller

2. Cost Center Number. 2750141

3. Sponsor Project Identification. NBS

4. Introduction. Accurate thermophysical properties data and predictive calculation methods for cryogenic fluids are needed to support advanced cryogenic technology projects. For example, liquefied natural gas is expected to supply an increasing percentage of the United States' energy requirements through 1990. Liquefaction plants, ships and receiving terminals are being constructed to transport and store natural gas in the liquid state (LNG). Accurate thermophysical properties data for LNG are needed to design low temperature processes and equipment. Accurate data will benefit the energy industries and the consumer by providing for safe and efficient operations and reduced costs.

5. Objectives or Goals. The objectives of this project are to provide comprehensive accurate thermodynamic, electromagnetic and transport properties data and calculation methods for technically important compressed and liquefied gases (helium, hydrogen, oxygen, nitrogen, methane, ethane, etc.) at low temperatures. Precise compressibility, calorimetric and other physical property measurements will be performed to fill gaps and reconcile inconsistencies. Definitive interpolation functions, computer programs and tables will be prepared for engineering calculations. The immediate goals of this work are to obtain accurate sound velocity and thermal diffusivity data for compressed and liquefied gases by using laser light scattering spectroscopy techniques. Sound velocity data are useful for testing the consistency of volumetric, calorimetric and thermodynamic properties data, and are potentially useful for density gauging applications. Thermal diffusivity data are required for performing thermodynamic and heat transfer calculations.

6. Background. When light is incident on a perfectly homogeneous fluid, the reradiated (scattered) light field sums to zero in all but the exact forward direction. For a "real" fluid, however, fluctuations, arising through various mechanisms, destroy the perfect homogeneity and result in the scattering of light in other directions as well. For example, thermally activated density fluctuations (phonons), propagating with the characteristic velocity of sound, give rise to scattered light which is Doppler shifted in frequency from the incident light frequency and whose spectrum contains information on the sound velocity and attenuation. Local non-propagating temperature fluctuations, which decay diffusively, give rise to scattered light in a narrow frequency band about the incident light frequency and whose spectrum contains information on the lifetime of the fluctuations (thermal diffusivity). since the frequency shifts are generally very small, it was not until the advent of the lasers with their extremely well defined frequency, that practical experiments using these phenomena were possible.

The application of laser light scattering techniques to obtaining thermophysical properties data was initiated to complement and check other measurement methods and to solve measurement problems inherent in more conventional methods. For example, laser light scattering techniques permit measurements of sound velocities for fluids under conditions for which sound absorption is too large to perform ultrasonic measurements; laser light scattering techniques permit measurements of thermal diffusivities under conditions for which convection interferes with measurements of thermal conduction. The feasibility of light scattering experiments to obtain data on binary diffusion coefficients has also been demonstrated. 
7. Program and Results. An apparatus has been assembled for laser light scattering spectroscopy measurements on compressed and liquefied gases (76-300 K, $35 \mathrm{MPa})$. The apparatus consists of a high pressure optical cell, a cryostat refrigerated by means of liquid nitrogen, an argon ion laser and low-level light detection equipment.

The light scattered from fluctuations in the fluid can be analyzed with either digital autocorrelation techniques for the examination of the very narrow lines associated with scattering from temperature fluctuations (Rayleigh scattering) or with a scanned Fabry Perot interferometer for the measurement of the Doppler frequency shifts associated with the scattering from propagating density (pressure) fluctuations (Brillouin scattering).

Apparatus for photon-counting and digital autocorrelation has been assembled, interfaced with computer facilities and programmed to enable on-line data accumulation and analysis. Initial problems associated with signal modulations from excessive building vibrations have been solved by levitating the apparatus on an air suspension system. A small, highly stable capacitor has also been designed, constructed and installed inside the scattering cell to permit the dielectric constant of the scattering fluid to be determined, which should allow more accurate fluid densities to be obtained for use in the data analysis. Apparatus tests on well characterized, strongly scattering, test fluids have been made to verify data analysis programs.

Extensive thermal diffusivity data have been obtained for methane. Measurements have been made along the coexistence curve, the critical isochore, and critical isotherm. The measurements extend outside the critical region as well as deep into the critical region. In the deep critical region the effect of temperature gradients and impurities have been investigated. Outside the critical region, these effects do not affect measurements beyond experimental accuracy. The range of the measurements extends from $150 \mathrm{~K}$ to $230 \mathrm{~K}$ and $3 \mathrm{~mol} / \mathrm{L}$ to $22 \mathrm{~mol} / \mathrm{L}$. The accuracy of the measurements is about 5\% in the critical region, increasing to 10 \% or greater further away. A detailed analysis of the data and experimental error is presently being made and a paper reporting the results is in preparation.

8. Problem Areas. Light scattering has proven to be a valuable tool for obtaining thermal diffusivity data on fluids. This is particularly true in a broad temperature and density range around the critical point, where more conventional experimental methods fail or are severely limited. The intensity of the scattered light however decreases drastically as one moves away from the critical region. Data accuracy in this region becomes limited by the statistical nature of the scattering process and the ability to maintain stability and precise experimental parameters over the extended periods of time necessary for data accumulation.

We have investigated other experimental techniques for obtaining widerange thermal conductivity measurements on compressed and liquefied gases and have decided that the transient hot-wire method offers the clearest advantages. Initial design steps have been taken including exploring the automation and electronics techniques that will be required for data acquisition and reduction. Several pieces of equipment have been ordered. 
9. Funding. January 1 - June 30, 1977

Man-years expended

0.5

Equipment and/or Services Purchased

$3.1 \mathrm{~K} \$$

Total Reporting Period Cost

$39.6 \mathrm{~K} \$$

Balance Remaining

$40.3 \mathrm{~K} \$$

10. Future Plans.

Objectives and Schedule: Quarter

Measure, analyze and report

thermal diffusivity

coefficient data for

methane in the critical region.

Design, construct and performance test transient hot-wire thermal conductivity apparatus. 
1. Title. PROPERTIES OF CRYOGENIC FLUID MIXTURES

Principal Investigators. M. J. Hiza, A. J. Kidnay (part-time), and R. C. Miller (part-time).

2. Cost Center Numbers. 2750142, 2750145 and 2754574

3. Sponsor Project Identification. NBS, NBS (OSRD), AGA

4. Introduction. Accurate thermodynamic properties data and predictive calculation methods for mixtures of cryogenic fluids are needed to design and optimize low temperature processes and equipment. This project provides new experimental measurements on equilibrium properties and compilations of evaluated equilibrium properties data which are suitable for direct technological use or for the evaluation of predictive calculation methods.

5. Objectives or Goals. The overall objectives of this project are to provide critically evaluated data, original and from other sources, on the phase equilibria and thermodynamic properties of cryogenic fluid mixtures. The program has been divided into the following elements:

a) Preparation of a comprehensive bibliography on experimental measurements of equilibrium properties for mixtures of selected molecular species of principal interest in cryogenic technology.

b) Selection and/or development of methods for correlation, evaluation and prediction of equilibrium properties data.

c) Retrieval and evaluation of experimental data for specific mixture systems selected on the basis of theoretical and/or technological importance.

d) Preparation of guidelines for future research based on the deficiencies noted in (a), (b), and (c).

e) Performing experimental research to alleviate deficiencies and provide a basis for improvement of prediction methods.

6. Background. A physical equilibria of mixtures research project was established in the Cryogenics Division in 1959. The initial effort, based on a bibliographic search and other considerations, was directed toward the acquisition of new experimental data on the solid-vapor and liquid-vapor equilibria and physical adsorption properties for a limited number of binary and ternary mixtures of components with widely separated critical temperatures. Most of the systems studied included one of the light hydrocarbon species -- methane, ethane, or ethylene (ethene) -with one of the quantum gases -- helium, hydrogen, or neon. The data for these systems led to significant improvements in the predictions of physical adsorption equilibrium and a correlation for the prediction of deviations from the geometric mean rule for combining characteristic energy parameters. In addition, significant new information was obtained for interaction third virial coefficients which was used in a correlation by one of our consultants, J. M. Prausnitz. The approach taken in this work has been as fundamental as possible with the intention of having an impact on a broad range of mixture problems.

Recent efforts have been directed toward problems associated with systems containing components with overlapping liquid temperature ranges, such as the nitrogen + methane system. 
7. Program and Results. The recent progress is summarized as follows:

a) A paper reporting new liquid-vapor equilibria measurements for the methane + ethane and the methane + ethylene systems has been published in the Journal of Chemical Thermodynamics 9, 167-78 (1977).

b) Data on the liquid-vapor equilibria, Henry's constants, excess Gibbs functions, liquid phase heats of mixing and excess volumes have been compiled, evaluated, and correlated for the methane + ethane system. A paper discussing this work is now in editorial review. This paper will be published in the Journal of Physical and Chemical Reference Data.

c) An equation of state, recently proposed by Peng and Robinson, has been optimized to represent the phase equilibria data for the nitrogen + methane and methane + ethane systems. The optimized equation has now been used to generate the nitrogen + methane $\mathrm{K}$-values and liquid and vapor equilibrium compositions for inclusion in the LNG Materials and Fluids user's manual. Work is now in progress to generate methane + ethane K-values and liquid and vapor equilibrium compositions for future inclusion in this manual. In addition, graphs of orthobaric liquid densities of methane and of nitrogen + methane mixtures (up to 5 mole percent nitrogen) were prepared from experimental data obtained in the LNG density project for inclusion in the LNG Materials and Fluids user's manual.

d) An empirical excess volume model has been developed based on orthobaric liquid density measurements for the pure components and binary mixtures completed in the LNG density project. This model has been tested on multicomponent LNG mixtures data and appears to be a simple and reliable method for predicting LNG densities from 105 to $120 \mathrm{~K}$. A paper discussing the development of this model is in editorial review and will be submitted to the Journal of Fluid Phase Equilibria.

e) Molar volume measurements were made at the University of Wyoming on one methane + ethane binary mixture and on four multicomponent mixtures containing either isobutane or normal butane, with and without nitrogen present. These measurements supplement the measurements made in the magnetic suspension densimeter and add evidence to substantiate the ability of correlation models to predict orthobaric densities of LNG. These results are now being compared with predicted results from the optimized excess volume model, and a paper is being prepared for the Journal of Fluid Phase Equilibria.

8. Problem Areas. None.

9. Funding. January 1 - June 30, 1977.

Man-years expended

Equipment and/or Services Purchased

Total Reporting Period cost

Balance Remaining
0.8

$4.8 \mathrm{~K} \$$

$64.3 \mathrm{~K} \$$

$43.5 \mathrm{KS}$ 
10. Future Plans.

Objectives and Schedule: Quarter

Evaluate, correlate and report liquid-vapor equilibrium properties data for methane + ethane mixtures.

Prepare and report graphs of liquid-vapor equilibrium properties data for nitrogen + methane mixtures.

Analyze and report total vapor pressure data and orthobaric liquid densities for methane + ethane mixtures.

Prepare and report graphs of liquid-vapor equilibrium properties data for methane + ethane.

Design, construct and performance test phase equilibria apparatus for total vapor pressure measurements on methane + isobutane mixtures.

Evaluate and report molar volume data on multicomponent mixtures of LNG components obtained at the University of Wyoming. 
1. Title. DENSITIES OF LIQUEFIED NATURAL GAS MIXTURES

Principal Investigators. M. J. Hiza, W. M. Haynes, R. D. McCarty and

W. R. Parrish

2. Cost Center Numbers. 2751574

3. Sponsor Project Identification. ING Density Project steering Committee; American Gas Association, Inc., Project BR-50-11.

4. Introduction. Accurate density measurements and calculational methods for liquefied natural gas mixtures are needed to provide a basis for custody transfer agreements and for mass, density, and heating value gauging throughout the fuel gas industry.

The basis for the custody transfer of natural gas is its heating value. It is difficult to determine and agree on the heating value of extremely large volumes of natural gas in the liquid state. For example, methods for calculating the heating value of a liquefied natural gas mixture require knowing its density, which in turn depends on its composition, temperature, and pressure. As the compositions of LNG mixtures vary considerably, depending on the sources of the gas and the processing conditions, accurate methods are needed for calculating liquid densities at arbitrary compositions, temperatures and pressures. The accuracy is important because of the extremely large volumes of liquid involved.

5. Objectives or Goals. The objectives of this work are to perform accurate $(0.1 \%)$ and precise $(0.02 \%)$ measurements of the densities of saturated liquid methane, ethane, propane, butanes, nitrogen and their mixtures mainly in the temperature range 105-140 $\mathrm{K}$, and to test and optimize mathematical models for calculating the densities of LNG mixtures at arbitrary compositions and temperatures.

6. Background. This project is being carried out at NBS because of the realization that equitable custody transfer agreements could be reached more readily if the density measurements and the evaluation and development of calculational methods were performed by independent professionals.

An apparatus incorporating a magnetic suspension technique has been developed for absolute density measurements on liquids and liquid mixtures, particularly at saturation, for temperatures between 90 and $300 \mathrm{~K}$. The estimated imprecision of measurement is less than $0.02 \%$ and the estimated inaccuracy is less than $0.1 \%$

7. Program and Results.

7.1 Measurements. All measurements on pure fluids, as well as binary mixtures have been completed and reported. $(1,2,3,4)$ Inconsistencies found in the butane-containing multicomponent mixtures (without nitrogen) were mentioned in the last report. These have been identified as probably arising from inadequate mixing within the cell. Previous data, published and unpublished, from the University of Wyoming and Elf Aquitane in France tend to support this supposition. This hypothesis was further supported by additional measurements performed on the Wyoming apparatus by a member of the NBS staff. (See report of Project 2750142 for more details.) The LNG Density Project Steering Committee has agreed to fund additional measurements to fully resolve the inconsistencies. The report on the previous NBS multicomponent mixtures data will therefore be delayed. The magnetic densimeter has been extensively modified to allow measurements to higher pressures. This work and the new apparatus is fully described in the report for cost center number 2750574 . 
A two part paper (experimental and calculational) will be presented at the Fifth International Conference on Liquefied Natural Gas in

Düsseldorf, Germany in August 1977.

7.2 Calculational Methods. Four promising methods of calculating the densities of liquid mixtures have been tested, modified and optimized utilizing the pure component and binary mixture data reported above. The four methods are a corresponding states method, a cell model, a hard-sphere model and an excess volume model. Computer programs have been written for all four methods and these have been used to calculate densities for comparison with the data for the mixtures measured. The calculated results agree with the experimental data to within $0.1 \%$ for all multicomponent mixtures except those containing methane and butanes but no nitrogen. If nitrogen is present the differences reduce to $0.1 \%$ or less. Comparisons of the four methods with both published and unpublished data from the University of Wyoming and Elf Aquitane in France show deviations of less than $+0.15 \%$ between measured and calculated densities. It is felt that only small corrections to the four methods will likely need to be made as a result of the new measurements proposed in 7.1 above.

Two of the four methods have been modified to account for the presence of small amounts of the pentanes. The modifications were based on published data for pure, normal and iso-pentane.

The results of the calculational efforts will be presented to the Fifth International Conference on Liquefied Natural Gas as mentioned in 7.1 above. A more complete account of the calculational methods study (including the four computer programs) has been prepared, reviewed and revised. This report will be published as an NBSIR in about two months.

8. Problem Areas. None.

9. Funding. January 1 - June 30, 1977.

Man-years expended 0.1

Equipment and/or Services Purchased

(Includes printing costs and travel expenses for ING-5 Conference)

Total Reporting Period cost

Balance Remaining

10. Future Plans.

Objectives and Schedule: Quarter

Prepare and distribute calculational methods report.

Performance test new magnetic densimeter PVT apparatus.

Measure, analyze, and report multicomponent mixture data, including selected LNG-like mixtures.

\section{References}

1. W. M. Haynes and M. J. Hiza, Orthobaric Liquid Densities of Normal Butane from 135 to $300 \mathrm{~K}$ as Determined with a Magnetic Suspension Densimeter, Advan. Cryog. Eng. Vol 21, 516-21 (Plenum Press, New York, 1976). 
2. W. M. Haynes and M. J. Hiza, Measurements of the Orthobaric Liquid Densities of Methane, Ethane, Propane, Isobutane, and Normal Butane, J. Chem. Thermodynamics Vol 9, 179-87 (Feb 1977).

3. M. J. Hiza, W. M. Haynes and W. R. Parrish, Orthobaric Liquid Densities and Excess Volumes for Binary Mixtures of Low Molecular Weight Alkanes and Nitrogen Between 105 and $140 \mathrm{~K}$, J. Chem. Thermodynamics Vol 9 (Sep 1977).

4. W. M. Haynes, M. J. Hiza and N. V. Frederick, Magnetic Suspensión Densimeter for Measurements on Fluids of Cryogenic Interest, Rev. Sci. Instrum. Vol 47, No. 10, 1237-50 (Oct 1976).

5. W. M. Haynes, A Simplified Magnetic Suspension Densimeter for Absolute Density Measurements, Rev. Sci. Instrum. Vol 48, 39 (1977).

6. W. M. Haynes, M. J. Hiza, and R. D. MCCarty, Densities of LNG for Custody Transfer, Proc. Fifth International Conference on Liquefied Natural Gas, Düsseldorf, Germany, Aug 29-Sep 1, 1977 (to be published).

7. D. E. Diller, ING Density Determination, Hydrocarbon Proc. Vol 56, No. 4, 142-4 (Apr 1977). 
1. Title. PROGRAM FOR REDUCING THE COST OF LING SHIP HULL CONSTRUCTION -PHASE II SHIP STEEL IMPROVEMENT PROGRAM

Principal Investigators. H. I. McHenry, M. B. Kasen, and R. P. Reed

2. Cost Center Number.

2753430 - LNG Ship Hull Materials (Shipyard Contracts)

2751430 - LNG Ship Construction Materials (Metallurgical Evaluation)

2752430 - LNG Ship Hull Materials (Fracture Properties)

3. Sponsor Project Identification. Maritime Administration Misc. P. 0. 400-58073.

4. Introduction. Construction of LNG tankers requires the use of fine grain normalized steels for the part of the hull structure that is cooled by the cargo to temperatures in the range of 0 to $-50^{\circ} \mathrm{F}$. Several ABS steels have satisfactory base plate properties but extreme care must be exercised during welding to avoid degradation of the steel adjacent to weld (the heat affected zone) to a level of toughness below U. S. Coast Guard requirements. Significant cost problems are being encountered by U. S. shipyards due to the resulting inefficient low-heat-input welding procedures that must be employed to meet the fracture requirements in the heat affected zone.

The feasibility of reducing the cost of LNG ship hull construction was investigated in Phase I of this project, leading to the Phase II program described below.

5. Objective. The objectives of the Phase II program are 1) to have the four major plate producers supply three LNG shipyards with production heats of ABS steels modified to possess improved transverse fracture properties at low temperatures, 2) to have the LNG shipyards evaluate these plates by qualifying optimum welding procedures in accordance with the USCG requirements, and 3) to provide a metallurgical evaluation of factors that influence heat affected zone toughness in the improved steels.

6. Background. Early in 1974, the Welding Panel of MarAd's Ship Production Committee recommended that a program be conducted to reduce the cost of ship hull construction. NBS was requested by MarAd to propose such a program to the LNG subcommittee of the Welding Panel at a meeting in Boulder in August. In mid-October, MarAd approved the initial phase of NBS's recommended program, i.e., to survey the problem and the technology available for its solution. On the basis of this survey and as the result of a meeting of the Welding Panel in March, 1975, a coordinated program involving the LNG shipyards, the steel suppliers, and NBS was recommended to MarAd and to the Welding Panel. This program was approved and work started in May 1975. Cost-sharing contracts for the evaluation of the improved steels were awarded in 1975 to the three participating shipyards: Avondale Shipyards, Inc., Newport News Shipbuilding and Drydock Co. and General Dynamics-Quincy Shipbuilding Division. A similar contract was signed with Lukens steel company to evaluate $\mathrm{Cb}-$ treated V-05l steel with and without sulfide shape control.

7. Program and Results. The shipyard evaluation phase of the ship steel Improvement Program was completed by the three participating shipyards: Avondale Shipyards Inc. (ASI); General Dynamics, Quincy Shipbuilding Division (GDQ); and Newport News Shipbuilding (NNS). Work is continuing on a similar evaluation being conducted by the Lukens steel company on $\mathrm{Cb}$-treated higher-strength-steel. The overall program, the results and the conclusions are summarized in this section. 
For the shipyard evaluation, the four major plate producers supplied the three participating LNG shipyards with production heats of ABS steels modified to possess improved transverse toughness properties at low temperatures. The LNG shipyards evaluated plates from these heats by qualifying optimum weld procedures in accordance with the USCG requirements. The specific steels evaluated by each shipyard and the test temperatures used in the weld procedure qualification testing are summarized below:

Shipyard

Avondale

Avondale

General

Dynamics

General

Dynamics

Newport News

Lukens

Lukens
Steel Producer

Armco

Armco

U.S. Steel

Bethlehem steel

Bethlehem Steel

Lukens

Lukens

\section{Test Temperature}

$-40^{\circ} \mathrm{F}$

$-60^{\circ} \mathrm{F}$

$-30^{\circ} \mathrm{F}$

$-60^{\circ} \mathrm{F}$

-30 and $-45^{\circ} \mathrm{F}$

$-40,-60,-75$

$-40,-60,-75$
Steel Grade

$\mathrm{V}-062 \quad(\mathrm{~S}<.01 \%)$

$\mathrm{V}-062$ (SSC)

CS (SSC)

A537A (SSC)

$\mathrm{V}-051$ (SSC)

$\mathrm{V}-051 \quad(\mathrm{Cb}, \mathrm{S}<.04 \%)$

$\mathrm{V}-051$ ( $\mathrm{Cb}, \mathrm{SSC})$

Each shipyard evaluated $1 / 2$ and 1-inch-thick plates from their heats of steel by qualifying optimum welding procedures in accordance with USCG requirements and by comparing these procedures with those currently used for conventional ABS grades. The processes (and positions) evaluated were: submerged arc (flat), gas metal arc (flat and vertical) and shielded metal arc (flat and vertical). The weld procedure qualification testing was limited to conducting the Charpy impact toughness traverse at the specified test temperatures. For these tests, specimens are cut transverse to the weld axis (and the plate rolling direction) with the notches normal to the plate surface.

The steels with sulfide shape control had excellent toughness at the test temperatures, however, this improved toughness was not consistently reflected in improved HAZ toughness. All of the ABS grades had satisfactory HAZ toughness when welded by the SMA or GMA processes. The SA welds were satisfactory for heat inputs up to 100 KJI for CS at $-30^{\circ} \mathrm{F}$, for $V-061$ for heat inputs up to $125 \mathrm{KJI}$ at $-60^{\circ} \mathrm{F}$ and for $\mathrm{V}-05 \mathrm{l}$ for heat inputs to $85 \mathrm{KJI}$ at $-45^{\circ} \mathrm{F}$. This represents an improvement over conventional steels for grades CS and $V-062$ and comparable results for $V-051$. The ASTM grade A537A modified with sulfide shape control exhibited improved base metal toughness but lower HAz toughness than the conventional grade. This steel exhibited unsatisfactory results at low and high heat inputs when tested at $-60^{\circ} \mathrm{F}$.

8. Problem Areas. The metallurgical factors that contribute to the degradation of HAZ toughness have not been clearly delineated in the program and it is unlikely that a satisfactory evaluation of these factors will be completed during the remainder of the program.

9. Funding. January 1, 1977 to June 30, 1977.

\begin{tabular}{l} 
Cost Center \\
\hline 2753430 \\
2751430 \\
2752430
\end{tabular}

\begin{tabular}{rl} 
Cost to & $6 / 30 / 77$ \\
\hline 144 & $\mathrm{~K} \$$ \\
64 & $\mathrm{~K}$ \\
48 & $\mathrm{~K} \$$
\end{tabular}

\begin{tabular}{cc} 
Balance \\
\hline 1 & $\mathrm{KS}$ \\
16 & $\mathrm{~K} \$$ \\
12 & $\mathrm{KS}$
\end{tabular}

10. Future Plans. The Lukens Steel Co. evaluation of Cb-treated V-05l should be completed by December 31, 1977. Work should start on the comparative testing program (Phase II of the Ship Steel Improvement Program) in the fall of 1977. 
1. Title. CUSTODY TRANSFER - LNG SHIPS

Principal Investigators. R. S. Collier and J. D. Siegwarth

2. Cost Center Number. 2750460

3. Sponsor Project Identification. Maritime Administration, Misc. P.O. $\# 400-79005$.

4. Introduction. In response to a request from the U.S. shipbuilding industry, $\overline{N B S}$ is conducting an independent design review of the shipboard custody transfer systems under the sponsorship of the Maritime Administration and in cooperation with the major U.S. shipbuilding companies.

5. Objectives. The objectives of this program are to 1) Identify the major technical areas relating to uncertainties in the measurement of total mass and total heating value, 2) Estimate uncertainties in the total mass and total heating value due to these identified factors, 3) Develop a proposed testing program for custody transfer system components, and 4) Investigate improved gauging techniques.

6. Background. Previous funding provided for the initial design review of ships designated by MA Design LG8-S-102a MA Hulls 289, 290, 291. The current funding provides for an extension of this program to include ships of other designs which are being built by the major U.S. shipbuilding companies and also to verify tank survey and gauging methods for LNG custody transfer.

7. Program and Results. Working relationships with four major U. S. shipbuilders have been initiated. Most of the problem areas which are common to custody transfer systems of all types have been identified and are listed as follows:

1. Density
a) accuracy
b) rangeability
c) stability

2. Tank Strapping (Tank Surveys)
a) thermal effects
b) loading factors
c) measurement techniques

3. Convection (Non-Uniform Density)
a) density or composition stratification
b) possible isolation of measurement stillwells

4. Tank Weathering
a) time changes in composition, stratification, etc.
b) composition measurement
c) sampling

5. Liquid Level/Total Volume Measurement

6. Pressure and Temperature Measurements (gradients included).

7. Electronic Signal Conditioning, Data Reduction, Analysis and Readout

One of the factors in shipboard evaluation of liquefied natural gas (LNG) energy content and cargo value is to determine the volume of ING in the ships' tanks. This is done by measuring the liquid level together with an independent determination of the ship tank capacity tables (volume 
vs. height, with list and trim corrections). Shipbuilders, transporters, buyers and sellers of LNG desire a total uncertainty in the ship tank capacity tables of $0.1 \%$ or less. This means that the inside surfaces of the tank must be. located to within something less than $1 \mathrm{~cm}$ for ship tanks of major dimension on the order of 36 meters. The tank survey is obtained under ambient conditions and corrections must be made for thermal contraction as well as stresses due to cooling and loading. The tank survey measures coordinate distances from target locations on the tank surface. These measurements are normally taken using a measuring tape, a theodolite, or a stereo-photogram. The tank surface is then obtained by modeling (mathematically) a surface passing through the measured target locations.

The stereo-photogrammetric technique is relatively new for these applications, but it is becoming accepted because of a number of attractive features: 1) The measurements can be made accurately, consistently, 2) There is a permanent visual record of the tank targets and their locations, 3) often, targets other than the primary ones can be located (scratch marks, seams, welds, etc.); These can aid, after the fact, if questions arise concerning tank modeling between primary target locations.

The NBS Cryogenics Division, with the assistance of the Mechanics and Applied Math Divisions, is serving in a third party role under a grant from the Maritime Administration to evaluate the accuracy of tank surveys and tank capacity tables for ships dedicated to LNG service. This is being done in cooperation with U.S. shipbuilders and their subcontractors involved in the construction of LNG tankers and with involvement of ship owners and operators and the buyers and sellers of LNG.

The NBS effort is being directed into four major areas, some of them posing unique measurement and analytical problems. The objectives of this work are:

1) to determine the accuracy of the survey techniques (primarily the photogrammetric techniques), as they are presently applied to locate the primary targets.

2) to evaluate methods for modeling the tank surface and to establish checks (or errors) between the model and the actual tank surface.

3) to calculate the probable error in the tank capacity tables as obtained by numerical integration of the model, this calculation being restricted to the empty tank at ambient temperature.

4) to evaluate the changes in tank dimensions (and resulting corrections to the capacity tables) due to thermal contractions and stresses from cooling and loading with an LNG cargo. This area of study includes the effects of possible hysteresis or changes in tank shape over a period of time due to continual use.

This last area poses some formidable measurement problems since the inside of the tank (or the outside for that matter) is not accessible under cryogenic conditions. If measurements are made at all, they must be done using a remote technique.

8. Problem Areas. A long baseline measurement in a horizontal direction is deemed necessary in order to minimize the estimated uncertainties in coordinate location. This may be difficult to do within the desired accuracy. Tape or wire measurements and microwave methods are being considered along with RF resonance methods.

9. Funding. January 1 - June 30, 1977.

Man-years expended

Total reporting period cost

Balance remaining
0.5

$37.5 \mathrm{~K} \$$

$26.5 \mathrm{~K} \$$ 
10. Future Plans.

1. NBS will continue to assess the ability of RF resonance measurements to give major dimensions of large empty tanks and also to evaluate its potential as a method of gauging LNG.

2. We will continue to work with the shipbuilders to assess the effects of loading and stresses due to thermal contractions on the projected tank capacity.

3. NBS will complete analysis of the coordinate data as it comes from the photogrammetric procedure and will evaluate results using independent data from the gauge rods and the redundant coordinates, in order to complete the assessment of the empty tank survey accuracy. 
1. Title. HEATING VALUE OF FLOWING LNG

Principal Investigators. J. A. Brennan.

2. Cost Center Number. 2756579

3. Sponsor Project Identification. Pipeline Research Committee (American Gas Association) PR-50-48.

4. Introduction. This project will test instrumentation for making heating value measurements in actual applications of flowing ING. Information from projects currently underway by Siegwarth (cost center 2757574) on densimeters, by Haynes and Hiza (cost center 2751574) on mixture densities and by Parrish (cost center 2750575) on LNG sampling will be utilized where appropriate to provide state of the art information.

5. Objectives. The objective of this program is to measure total heating value of ING flowing in a pipeline by the integration of individual measurements of flow, density and specific heating value. Flow measurement requires determination of flowmeter performance in line sizes larger than presently available calibration facilities. Therefore, a secondary objective is to establish appropriate flowmeter scaling laws.

6. Background. The LNG flow facility at NBS will be utilized to evaluate the response of the individual elements in the heating value measurement. Different compositions of LNG will be prepared to provide a range of densities and temperatures sufficient to determine any dependencies. A limited amount of sampling work is included to determine the relative importance of this parameter to the overall measurement.

Flowmeter scaling is being done utilizing the cryogenic and the water flow facilities at NBS and private LNG peak shaving facilities.

7. Results. A. Tests at NBS.

LNG flow tests run in conjunction with the sampling project (cost center 2750575) resulted in a continuation of the discrepancies described in the last report. These discrepancies were between the heating values calculated from gas analysis and measured on the calorimeter. As a result of those tests additional work has been done on the sampling project on other flow facilities to try to eliminate the problems encountered. Additional tests on the NBS flow facility are planned for the next reporting period to verify the solutions to the problems.

The benefits from the work done on the sampling project are obvious. Although never a part of this project, sampling has always been recognized as a vital element in the successful application of the measurement station concept. Therefore, the next series of flow facility sampling tests will have significant importance and any information obtained will be made available to this project.

B. Tests at Transco

The tests at Transco's peak shaving facility have been completed and the report is in progress. Considerable data were obtained during send outs during January. Not only were longer runs obtained, but runs at higher flow rates were also obtained.

All of the results will be included in a separate report now being finalized. 
C. Test Section Installation at Southern Energy.

Test section fabrication is underway. Considerable delay has been experienced in getting design problems worked out and fabrication procedures approved.

There are still some problems remaining with the densitometer but those should be worked out in the near future. The densitometer problems will not hold up the delivery of the test section to Southern for installation into the facility.

8. Problem Areas. The problems described above have resulted in delays that have prevented the calibrations required from taking place as planned and are now scheduled for the next reporting period. These calibrations will consist of a water calibration of the flowmeter, a flowing liquid nitrogen test on the densitometer and a non-flowing liquid methane test on the densitometer.

The delays have also resulted in all the remaining funds being expended so it was necessary to request an additional $\$ 15,000$ to complete this phase of the project.

9. Funding. January 1 - June 30, 1977

Man-years expended

Total reporting period costs

Balance remaining

0.5

$40.0 \mathrm{KS}$

0

10. Future Plans. Completion of the report of results and all the necessary calibrations of the instrumentation for Southern's import terminal will be done as rapidly as possible. Installation of the recording equipment at Southern will be completed when convenient for Southern after the changes are checked out. 
1. Title. LNG DENSITY REFERENCE SYSTEM

Principal Investigators. J. D. Siegwarth and J. F. LaBrecque

2. Cost Center Number. 2757574, 2750161

3. Sponsor Project Identification. American Gas Association, Inc., Project BR-50-10; National Bureau of Standards

4. Introduction. A density reference system has been developed to evaluate the ability of commercially available instruments to measure densities of LNG directly. Density is an essential measurement in determining the total energy content of natural gas reservoirs. This effort is oriented towards metrology, whereas the output from cost center 2751574 will provide basic reference data on pure liquids and mixtures to evaluate methods for calculating the density indirectly.

5. Objectives. The objective of this research is to evaluate the density measurement capability of commercially available meters. From the commercial meters we will attempt to select one or two capable of performance as transfer standards, in order to provide traceability of accuracy to field density measurement systems.

6. Background. The density reference system project was initiated in 1973. Since that time the reference system has been designed, constructed, and is now in operation, evaluating commercial density metering systems.

7. Program and Results. The second series of densimeter tests has been completed. A final report and an updated accuracy statement for the density reference system (DRS) are in preparation. The occasion to occasion shift in the DRS has been eliminated, and the estimated inaccuracy of a future measurement has been established to be $\pm 0.076 \%$. The densimeters tested have been found to have satisfactory prêcision but some are lacking satisfactory calibrations for LNG service.

A final draft of the densimeter report is written along with a final draft of the DRS Provisional Accuracy statement. The review should be completed and the reports ready for printing by August 1.

8. Problem Areas. The DRS is performing in a satisfactory manner but the sample container is too small and too inflexible to permit testing some other densimeters which we would like to test.

9. Funding. January 1 - June 30, 1977.

Man-years expended

Total reporting period cost

Balance remaining

0.4

$25.0 \mathrm{K \$}$

10. Future Plans. The DRS may be modified to take larger commercial densimeters. The DRS will be used to evaluate and calibrate transfer standards for use in calibrating densimeters at other locations. A transfer standard will be sent to Gaz de France, Paris, to intercompare our two calibration systems. 
1. Title. LNG SAMPLING MEASUREMENT STUDY

Principal Investigators. W. R. Parrish, J. M. Arvidson and J. D. Siegwarth

2. Cost Center Number. 2750575

3. Sponsor Project Identification. LNG Sampling Measurements Supervisory Committee.

4. Introduction. Composition is used to determine both the heating value and the quantity (through density) of LNG shipments. Thus, any error in composition doubles when calculating the total heating value and dollar value of a LNG tanker cargo. Compositions are determined by sampling LNG, on either a batch or continuous basis, and analyzing the vaporized mixture. Although several sampling techniques exist, none have received widespread acceptance in the LNG industry. Also, a standard technique has not been established for analyzing the vaporized sample.

5. Objectives or Goals. The objectives of this work are to evaluate existing sampling techniques appropriate to LNG systems and to recommend the most accurate analytical technique. Only sampling devices applicable to pipelines are being considered. The sampling techniques are judged on:

a) representativeness of sample,

b) insensitivity of results to composition, temperature, pressure, degree of liquid subcooling, flow rate and operator, and

c) simplicity.

Initial evaluations will be made in a laboratory-scale apparatus; final evaluation of the most promising sampling techniques will be performed in the LNG flow facility.

6. Background. This work is being performed because there is a need to determine the best means for obtaining the composition of LNG shipments. Current LNG buying contracts include specifications on when and how many liquid samples are to be taken but omit the sampling technique to be used. The evaluation of sampling techniques by NBS is expected to lead to the acceptance of the most accurate composition determination method by all parties involved in LNG custody transfer.

7. Program and Results.

A. Laboratory Results

The laboratory-scale sampling tests were completed in May. It was found that the sampling imprecision (one standard deviation) was typically around $0.04 \%$ in the heating value; this is roughly twice the imprecision obtained for gas analysis alone. The reason for the increased scatter was never found. Two sampling probes, a side tap and an upstream-facing pitot tube were tested; the side tap gave slightly more reliable results. Of the three different sample conditioners (i.e., vaporizers) tested, the simple heated tube vaporizer produced the best results.

The laboratory results showed that the only operating parameters that were important were the sampling rate and the time averaging of the vaporized sample. It was found that high sampling rates are necessary for obtaining representative samples. Samples taken without time averaging had roughly 100 times the scatter of the time averaged samples.

Variables tested, but not showing an effect on sampling precision, included operating temperature and pressure, degree of subcooling at the sample point (at least for greater than $\sim 0.3 \mathrm{~K}$ subcooling) and LNG flow rate. 
The sampling precision was not affected by sampling from a LNG stream in laminar or turbulent (Reynold's numbers of 1600 to 37,000 ) flow.

B. Tests Aboard the LNG Tanker El Paso Consolidated

A LNG sampling system was designed, installed and operated aboard the El Paso Consolidated in June. The ING sampler was put into the heater going to the ship's stream vaporizer; a similar sampling system (excluding the sample vaporizer) was installed in the vaporizer outlet header for collecting vapor samples. Although all of the data have not been analyzed, a test having 7 sets of samples showed that the difference in the average heating values of the liquid and vapor samples was $0.04 \%$; the estimated standard deviation was $0.045 \%$ for both types of samples. This is only slightly greater than the estimated standard deviation of $0.03 \%$ for gas analysis alone.

\section{LNG Flow Facility Tests}

Final sampling tests will be made in the LNG Flow Facility at Boulder. The variables to be considered will include the level of insulation, the heat source for sample vaporization and the sampling rate. By combining all of the sampling data we hope to establish a criterion for setting the sampling rate.

D. Gas Analysis

Previous work had established that gas chromatography is the best method for measuring the composition of vaporized LNG mixtures. The final phase of this work will be to recommend column configurations, determine optimum operating procedures and establish tolerance levels for operating variables. Intercomparisons between two gas chromatographs and two data processors will be made.

8. Problem Areas. None.

9. Funding. January 1 - June 30, 1977.

Man-years expended .75

Total reporting period cost

Balance remaining

$60 . \mathrm{KS}$

$41 . K \$$

10. Future Plans.

objectives and schedule:

Complete all tests and write

final report. 
1. Title. SURVEY OF CURRENT LITERATURE ON LNG AND METHANE Principal Investigator. Neil A. Olien

2. Cost Center Number. 2759574

3. Sponsor Project Identification. American Gas Association, Inc., Project BR-50-10.

4. Introduction. It is important that all NBS personnel working in LNG, as well as the AGA and others, keep up with what is going on throughout the world in the LNG field. This project is designed to provide the Current Awareness and other information services to allow workers to keep abreast of new research and other developments.

5. Objectives or Goals. We will publish and distribute each April, July, October, and January a listing of all significant papers, reports, and patents relating to methane and LNG properties and technology. The references will be listed under convenient subject headings. The Quarterly will be distributed to all interested AGA member companies and be made available to the general public on a subscription basis. In addition, LNG related information will be entered into the Cryogenic Data Center's Information System for quick retrieval. A continuing awareness of the current publication scene is maintained for any new periodicals to be reviewed cover-to-cover. Finally we will update and make available comprehensive bibliographies on the properties and technology of LNG. There are four bibliographies involved: methane properties, methane mixtures properties, processes and equipment involving methane and LNG, and patents relating to methane and LNG technology. These four will be updated annually.

6. Background. In 1969 we made a thorough review of the world's publications to determine which periodicals and abstracting services should be scanned cover-to-cover to adequately encompass the LNG field. The result is that we now scan over 330 primary publications and nearly 25 secondary publications. Of these, approximately one-third are directly related to LNG. In addition, we have increased our coverage of the energy field to include hydrogen as a future fuel. Much of this information is also pertinent to LNG and as such is listed in our LNG-related publications. Our Current Awareness Service has been published weekly since 1964 (beginning in 1975 the publication became biweekly) and the Liquefied Natural Gas Survey has been published quarterly since 1970 .

7. Program and Results. Four issues of the LNG Quarterly are prepared each year and distributed. There are now 134 subscriptions going to AGA Member Companies and 154 to other subscribers.

The four comprehensive bibliographies mentioned in section 5 have been reviewed and shortened, and more selective bibliographies have resulted. The latest versions were completed as of January 21, 1977.

B-1525 THE THERMOPHYSICAL PROPERTIES OF METHANE AND DEUTERO-METHANE IN THE SOLID, LIQUID AND GASEOUS PHASES - A SELECTED BIBLIOGRAPHY. Indexed by property, phase and author, 100 pages (Jan 1977). (\$10.00).

B-1526 THE THERMOPHYSICAL PROPERTIES OF METHANE MIXTURES - A SELECTED BIBLIOGRAPHY. Indexed by property, system and author, 166 pages (Jan 1977). (\$15.00).

B-1524 PROCESSES AND EQUIPMENT INVOLVING LIQUEFIED NATURAL GAS AND METHANE - A SELECTED BIBLIOGRAPHY. Indexed by subject and author, 285 pages (Jan 1977). (\$25.00). 
B-1527 PATENTS RELATING TO METHANE AND LNG TECHNOLOGY - A SELECTED BIBLIOGRAPHY. Indexed by author, 150 pages (Jan 1977). $(\$ 15.00)$.

Over the past six years we have distributed over 500 copies of these and the comprehensive bibliographies.

8. Problem Areas. None.

9. Funding. January 1 - June 30, 1977.

Labor

Other costs

Total

$4.6 \mathrm{~K} \$$

$\frac{1.1 \mathrm{KS}}{5.7 \mathrm{KS}}$

Remaining

$11.0 \mathrm{~K} \$$

10. Future Plans. Issue 77-2 was delivered to the printer the second week of July and should be distributed by the end of July. 
1. Title. LIQUEFIED NATURAL GAS TECHNOLOGY TRANSFER

Principal Investigator. D. B. Mann

2. Cost Centers. 2750403, 2751403,2752403,2750570,2754574, 2758574 and 2750127 .

3. Sponsor Project Identification. Maritime Administration, Miscellaneous Purchase Order No. 400-79005; American Gas Association, Inc. Project BR 50-10; American Bureau of Shipping letter dated 21 November 1975; and NBS-Office of Standard Reference Data.

4. Introduction. The liquefied natural gas program at the Cryogenics Division of NBS-IBS/Boulder represents an investment by industry and government agencies of over $\$ 5$ million over the past six years. This investment was designed to develop reference quality properties data for both fluids and materials and instrumentation and measurement technology for the use of the LNG and related industries. Information developed under this program must be transmitted to the ultimate user in a timely and useful format. The classical publication methods of NBS most certainly provide the scientist and research engineer information in a form most useful to the academic or near academic community. However, as a result of extensive assessments of user requirements, it was found that an additional effective mode for technology transfer would be an LNG Materials and Fluids User's Manual. A complete outline and planned table of contents has appeared in previous semi-annual reports. The Maritime Administration of the Department of Commerce and the American Bureau of Shipping have agreed to sponsor the first year's efforts on the materials section, and the American Gas Association, Inc. and the NBS Office of Standard Reference data have agreed to sponsor the section on fluids and fluid mixtures. The project was begun on April 1, 1976.

5. Objectives. The Liquefied Natural Gas Materials and Fluids User's Manual will provide a method of quick dissemination of property data and related information for the effective generation, utilization and transportation of LNG. The object is to improve technology transfer from the current NBS Cryogenics Division LNG physical measurements program to the users, including federal agencies, the states and industry. For the purpose of this data book, liquefied natural gas is defined as a cryogenic mixture (at less than approximately $150 \mathrm{~K}$ ) of hydrocarbons, predominantly methane, with less than a total of $20 \%$ of the minor components ethane, propane, iso and normal butane, and nitrogen as an inert contaminant. LNG materials will be those associated with the liquefaction, transport and storage of liquefied natural gas.

6. Background. The user's manual is only one of a number of information dissemination methods used to provide workers in the liquefied natural gas (LNG) industry with properties data of known quality in a format consistent with the requirements of the intended user. In the case of the LNG user's manual the intended audience is the field engineer, plant manager, ship designer or process engineer interested in a ready reference of assessed quality for data to be used in conceptual design, process monitoring, process analysis, and intercomparisons where precision and accuracy are secondary to specific problem solutions. The hierarchy of accuracy and precision will be defined and traceable through references to scientific and engineering literature.

Data is classified into three groups by the NBS Cryogenics Division.

Group 1. Data which has been generated experimentally by NBS, or has been assessed, evaluated or experimentally verified by NBS.

Group 2. Data which has been assessed and evaluated by NBS. 
Group 3. Data available in the scientific engineering literature through the NBS Cryogenic Data Center or elsewhere. No NBS evaluation or assessment has been made at this date.

In general, all data included in the LNG user's manual will be from groups 1 and 2. Few new assessments or correlations are anticipated or required for this work.

Data will be presented primarily in graphical form. Tables and analytical expressions will be used only where absolutely necessary. Graphs and charts will be in loose-leaf form for ease of updating and additions. This form will also allow immediate implementation for data already available under the NBS LNG program and will provide a convenient form for the output of data from existing projects. The user's manual will not be a substitute for traditional publications in the scientific literature where measurement science, technique, precision and accuracy are paramount, but will provide the data and references for the necessary assessment by the user.

The publication of both graphical and tabular data will be in a dual system of physical units. These units will be the traditional LNG industry British system of BTU, pound, degree Fahrenheit and the SI system of joule, kilogram and kelvin. It is the intent to give equal weight to each system of units.

Nine structural metals have been selected with additions possible upon consultation with the sponsors. Primary emphasis in the fluids section will be on data for pure methane, pure nitrogen, and methane-nitrogen mixtures.

7. Program and Results. The distribution of the user's manual has been unavoidably delayed over our original timetable. However, all charts are presently at the printer and we anticipate distribution sometime in September of this year. The first edition will include 138 charts, 8-1/2" x 11", and six 22" x 34" charts on the properties of pure fluids methane and nitrogen. Structural materials data for aluminum alloys (3003, 5083, 6061), invar (Fe-36Ni), nickel steels (2-1/4, 3-1/2, 5 and $9 \% \mathrm{Ni})$ and stainless steels $(304,304 \mathrm{~L}, 310$ and 316 ) are included in the first edition. Elastic, thermal and mechanical properties of these materials are presented in graphical format. Data on pure fluid methane, on nitrogen and on methane-nitrogen mixtures are also included, and cover thermodynamic, transport and electromagnetic properties.

8. Problem Areas. Delays in final preparation of print-ready copy have hopefully been eliminated; future supplements should not suffer from these delays.

9. Funding. January 1 - June 30, 1977.

Labor - man-years expended

Funds expended

Balance remaining (first edition)

0.5

$43.0 \mathrm{KS}$

0

10. Future Plans. The second year of this user's manual has been funded by the Maritime Administration, the American Gas Association (Gas Research Institute) and the Office of Standard Reference Data (NBS). D. E. Diller has accepted the general editorship of this supplement and anticipates 90 charts in the supplement. It is planned to add additional properties of structural materials and a section on insulations. In addition, data for pure ethane and for mixtures containing methane will also be included. 
1. Title. OIML JOINT SECRETARIAT ON LNG MEASURENENTS

Principal Investigator. Douglas Mann

2. Cost Center Number. 2750104

3. Sponsor Project Identification. American Gas Association, Inc., NBS-Office of International Standards; and NBS-Cryogenics Division.

4. Introduction. The liquefied natural gas program of the National Bureau of Standards Cryogenics Division has, over the past five years, provided the gas industry and interested Government agencies with properties data on materials and fluids, instrumentation, and measurement assistance in the support of commerce in this significant and growing segment of the supplementary fossil energy supply. Support of this program by the American Gas Association, Inc. and Federal Government agencies such as the Maritime Administration (MarAd), NASA, GSA, Federal Power Commission and the NBS-Office of Standard Reference Data has provided a basis for the national acceptance of the results of the NBS LNG program. Through the U.S. membership in the International Organization of Legal Metrology there exists, at the present time, an opportunity to extend, internationally, the utility of data and measurement practice developed under our joint government/industry program. We have been requested (by OIML membership) to establish an LNG Measurement Secretariat within OIML which, if implemented, would provide a significant international forum for the results of our joint work. It is believed that a joint secretariat with the LNG industry would provide the most effective means of accomplishing these objectives.

5. Objectives or Goals. Our objective is to accomplish the following goals within the next three years:

a) to establish U.S. (NBS) thermophysical properties data for LNG as the standard data in international usage.

b) to establish U.S. (NBS) materials property data used in fabrication and construction of LNG facilities (liquefiers, storage, transport) as the standard data in international usage.

c) to establish U.S. (NBS) approved measurement technology and instrumentation as related to LNG (pressure, temperature, density, liquid level, flow) as the standard in international LNG trade. The precedent has been established with the successful completion of the joint NBS-CGA cryogenic flow measurement program which has resulted in the adoption of a cryogenic flow measurement code by the National Conference on Weights and Measures. We wish to extend this code on an international basis.

d) to establish and maintain the leadership of U.S. science, engineering, and industry in the research, technology, manufacture and marketing of instruments and measurement systems for liquefied natural gas.

6. Background. OIML was founded in 1955 to promote intergovernmental cooperation in the field of legal metrology which relates to the compatibility of standards of measurement and the legislation and government regulations which may affect such standards of measurement. OIML recommends uniform international requirements for scientific and measurement instruments used in industry and commerce and works out model laws and regulations for consideration by member nations; and, in addition, serves as a center of documentation and information exchange in legal metrology. At present 43 nations are members of this intergovernmental organization.

The United States joined OIML in 1972 (the Senate by resolution of August 11, 1972 gave its advice and consent to the accession of the U.S. to the convention establishing OIML). The responsibility for managing U.S. participation in OIML ivas assigned to the Department of Commerce 
and has since been delegated by the Department to the National Bureau of Standards (NBS). Under the general guidance of the Department of State and the Secretary of Commerce, NBS is directly responsible for formulating and implementing U.S. policy towards OIML. U. S. participation in the organization is deemed important for two reasons: first, to protect and enhance some $\$ l$ billion worth of scientific and measurement instruments exported each year by U. S. firms and to insure equity in the trade of commodities measured by these instruments; and second, to maintain the U.S. as the world leader in the field of metrology.

In the spring of 1975 at a meeting in Paris of the International Committee of Legal Metrology, the French and U.S. representatives discussed the possibility of creating a new Reporting Secretariat No. 13 on "Liquefied Natural Gas (LNG) Measurement". The U. S. representative, W. E. Andrus, Jr. of NBS, agreed to explore the possibility with U. S. industry and interested government agencies. These discussions resulted in a decision to propose a joint Secretariat with the American Gas Association and NBS-Cryogenics Division in order to best accomplish the tasks. These conclusions were reached during several meetings extending through the latter part of 1975 and early 1976.

7. Program and Results. An overall scope for recommendations for LNG measurements was completed. The measurements would apply to both static measurements (land based storage, marine tanker at dock site, large tanks at dock site and highway or road trailer) and dynamic measurements (pipeline). It was suggested then that the measurements be divided into two areas: static and dynamic mass measurements and static and dynamic gross heating value measurements.

Recent developments, such as the adoption by the National Conference on Weights and Measures of the model code "Cryogenic Liquid Measuring Devices," may affect the manner in which LNG measurements are treated by OIML. A similar code, developed by European industry, indicates that enough interest is developing in this high technology area that recommendations by OIML should not be limited to LNG, but should include other cryogenic fluids. Representatives of NBS will meet with PTB (West Germany) and SIM (France) to explore this possibility during August.

8. Problem Areas. None.

9. Funding. January 1 - June 30, 1977.

Labor - Man-years expended

Funds expended

0.1

Balance remaining

$11.0 \mathrm{KS}$

$11.0 \mathrm{~K} \$$

10. Future Plans. Two areas will be explored. The first concerns expanding the scope of the LNG measurements to include other cryogenic fluids and thereby taking advantage of existing codes and standards within the U.S. and Europe. Second, continued development of the scope for LNG measurements to identify recommendations already available under OIML and those which must be written separately. 
1. Title. FEDERAL POWER COMMISSION CONSULTATION

Principal Investigators. D. B. Chelton, T. R. Strobridge and A. F. Schmidt.

2. Cost Center Number. 2750404

3. Sponsor. Federal Power Commission - Bureau of Natural Gas -- letter agreement dated 4 June 1973.

4. Goals. The Cryogenics Division will provide consultation and advisory services to the Federal Power Commission on the cryogenic safety and the design aspects of current applications before the FPC for authorization of LNG terminal and storage facilities. These services cover properties of cryogenic environments, insulation systems, cryogenic safety, thermodynamics, heat transfer, instrumentation, and cryogenic processes such as refrigeration and liquefaction.

5. Background. Cost Center initiated July 7, 1973.

6. Program and Results. The status of those facilities presently under the jurisdiction of the Federal Power Commission and subject to our review are outlined in the following table.

Elements of the facilities that are subject to review are the land-based cryogenic storage tank components, bounded by the tanker or barge, the inlet and distribution pipelines. These include, but are not limited to the transfer lines, the storage tanks, the vaporizers and the process piping as it interacts with the storage tanks. It is essential that the reviews cover the operation, maintenance and emergency procedural

philosophies for each terminal. Based upon these studies, reports are submitted to the staff of the FPC setting forth the technical evaluations and conclusions on each proposal.

Emphasis is placed on the safety aspects of the facilities including their possible interactions with the surrounding areas. The impact of engineering design such as appropriate use of existing technology and material selection for structural integrity must be assessed. The basis of review includes various codes and standards, prior experience, precedent and engineering knowledge. Vapor cloud generation and plume dispersion is considered a subject beyond our area of expertise.

7. Funding.

FY 77 Allocation

$70 \mathrm{~K} \$$

Expended January 1, 1977-June 30, 1977 30K\$

3. Future Plans. At the present time there are several pending applications, but detailed information is not yet available. It is anticipated that additional facilities will be reviewed as applications are made to the Federal Power Commission. 


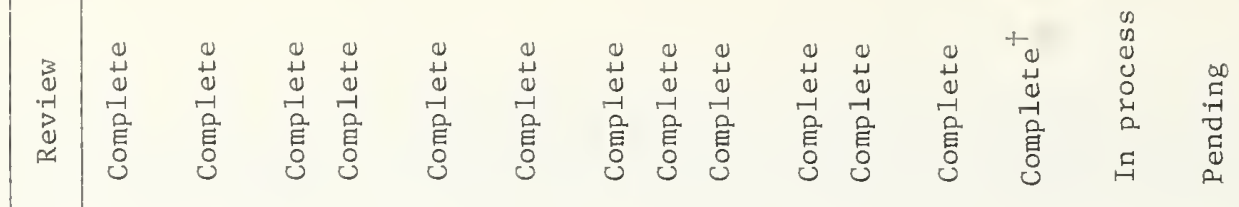

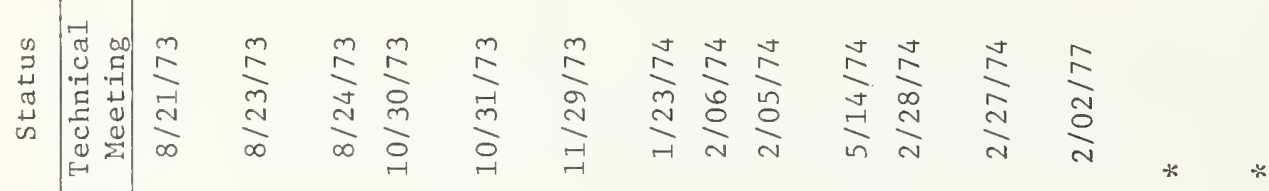

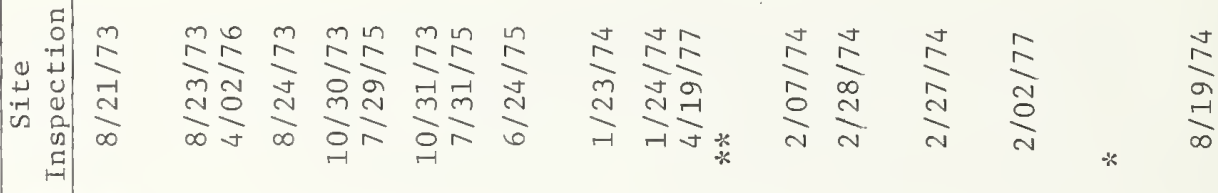

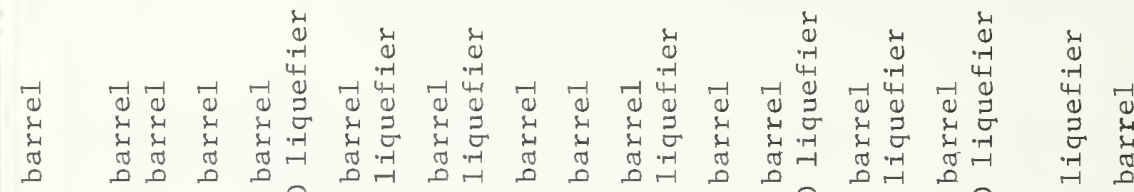

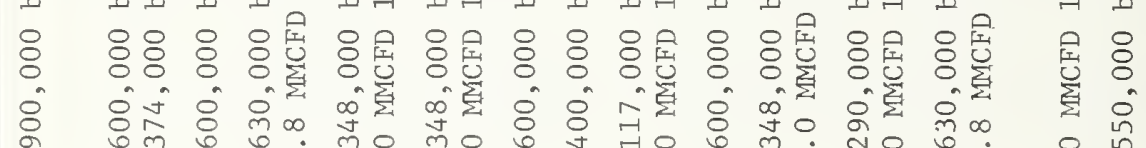

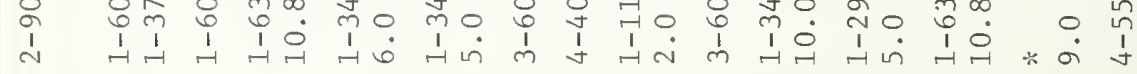

\section{굴}

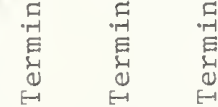

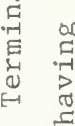

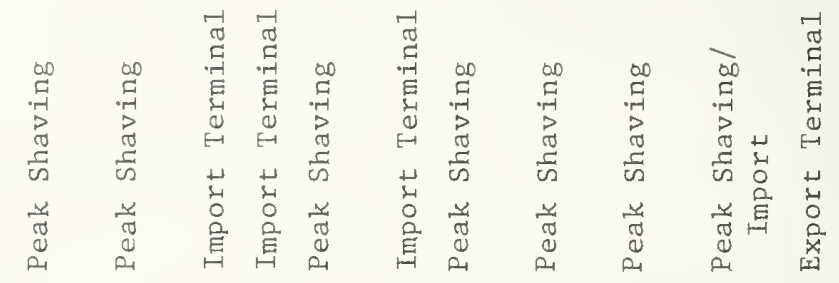
$\stackrel{-1}{\infty}$

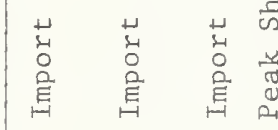

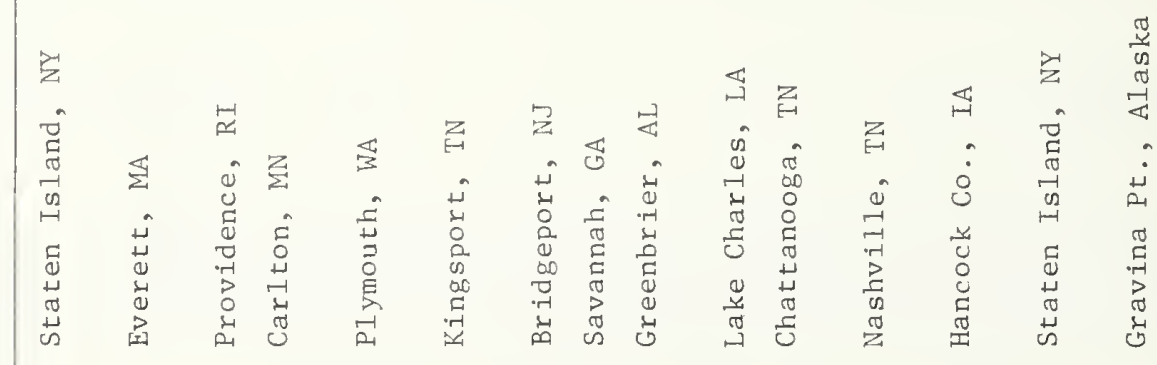




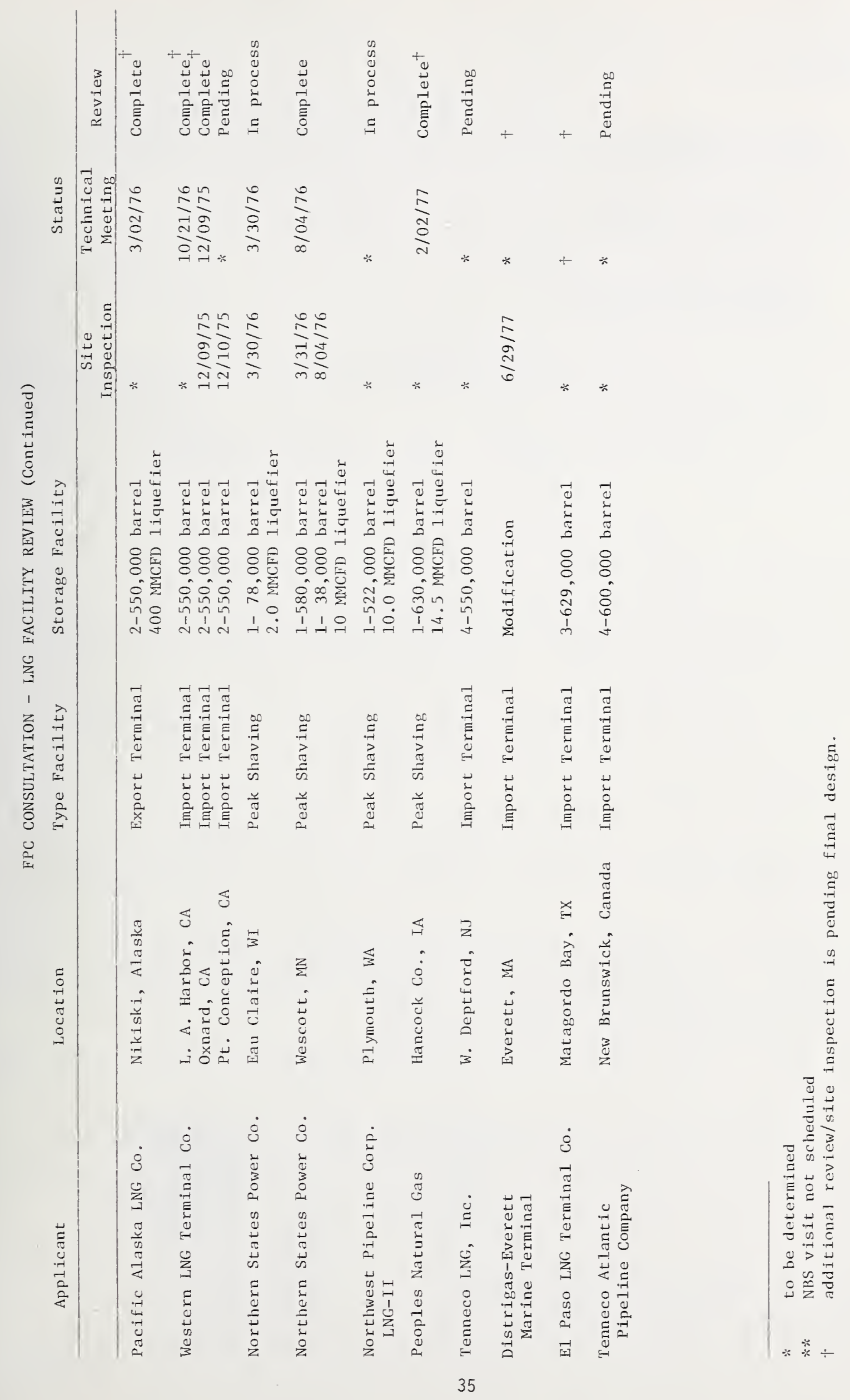


NBS-114A (REV. 7.73)

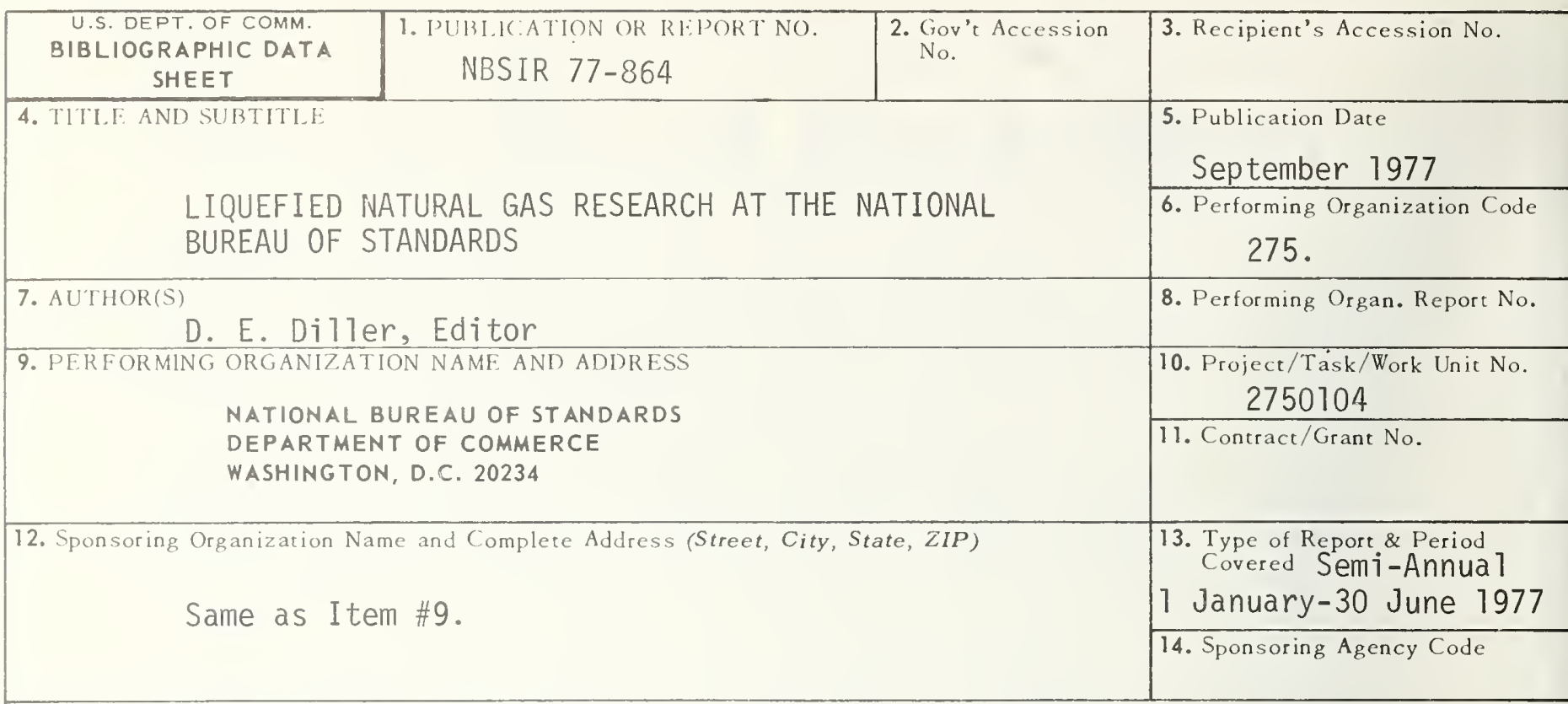

15. SUPPLEMENTARY NOTES

16. ABSTRACT (A 200-word or less factual summary of most significant information. If document includes a significant bibliography or literature survey, mention it here.)

Twenty-six cost centers, supported by six other agency sponsors in addition to NBS, provide the basis for 1 iquefied natural gas (LNG) research at NBS. During this six-month reporting period the level of effort was over 20 man-years/year with funding expenditures of over $\$ 500,000$. This integrated progress report, to be issued in January and July, is designed to:

1) provide all sponsoring agencies with a semi-annual and annual report on the activities of their individual programs;

2) inform all sponsoring agencies on related research being conducted at the Cryogenics Division;

3) provide a uniform reporting procedure which should maintain and improve communication while minimizing the time, effort and paperwork at the cost center level.

The contents of this report will augment the quarterly progress meetings of some sponsors, but will not necessarily replace such meetings. Distribution of this document is limited and intended primarily for the supporting agencies. Data or other information must be considered preliminary, subject to change and unpublished, and therefore not for citation in the open literature.

17. KEY WORDS (six to twelve entries; alphabetical order; capitalize only the first letter of the first key word unless a proper name; separated by semicolons)

Cryogenics; liquefied natural gas; measurement; methane; properties; research.

18. AVAlLABILITY
$\forall 7$ For Official Distribution. Do Not Release to NTIS
$\square$ Order From Sup. of Doc., U.S. Government Printing Office
Washington, D.C. 20402, SD Cat. No. C 13
$\square$ Order From National Technical Information Service (NTIS)
Springfield, Virginia 22I51

\begin{tabular}{|l|l|}
\hline $\begin{array}{l}\text { 19. SECURITY CLASS } \\
\text { (THIS REPURT) }\end{array}$ & 21. NO. OF PAGES \\
UNCL ASSIFIED & 22. Price \\
\hline $\begin{array}{l}\text { 20. SECURITY CLASS } \\
\text { (THIS PAGE) }\end{array}$ & USCOMM-DC 29042-P74 \\
\hline
\end{tabular}

